doubt as to there being a croupous as well as a diphtheritic membrane in the eye. This has been the outcome of many observations by careful observers.

DR. J. B. Hamilton said that the contra-indications for tracheotomy were of importance as regards the relation between physician and surgeon. In one case which he had been called to operate upon he found a double pneumonia and a capillary bronchitis. Considering that the patient was certain to die he refused to do the operation as it would simply bring discredit to the profession. The invasion of the larynx is, in his opinion, the indication for operation. The operation itself may be fatal when it is followed by pneumonia or bronchitis. Hæmorrhagic cases are not relieved by the operation. There are some cases in which the hæmorrhage is from the back of the nose that are temporarily relieved by tracheotomy, but death from exhaustion is apt to ensue. This complication he thinks is a more common one than is generally supposed. He regards the operation as one of the most trying ones in surgery.

Dr. L. TYLER in closing said that Dr. Thompson's remarks show that he is in the foremost ranks of one class of thinkers. He could not agree with him that tracheotomy was a difficult operation, and without adnitting the possession of any special cut-throat proclivities he thought it a most fascinating one. While pneumonia following tracheotomy is a remote possibility the very possibility is an indication for an early operation before the lungs have become so congested as to make its sequence more probable. We must understand that the operation is a curative one. As a dernier ressort it may only be productive of euthanasia and anticipatory of a fatal issue from asphyxia. Properly speaking there is no such thing as the croupous membrane mentioned by Dr. Burnett, but rather a dipthheritic membrane. Croup is a symptom of diphtheria, and, in his opinion, the amount of membrane depends upon the extent and degree of the inflammation. He agrees with Dr. Lovejoy in the opinion that exposure to cold is a cause of diphtheria and he thought he had been able to trace cases to this origin. Dr. Fernald, in his paper at the previous meeting, had given a strong argument in favor of trypsin as a solvent of the membrane and he would join in recommending its use upon the strength of the results which he had experienced in his case of aural diphtheria.

\section{FOREIGN CORRESPONDENCE}

\section{MUNICH.'}

The University-Over crowding in the Profession -Doctors and Rich Wives-Nussbaum; his WorkExtirpation of Struma-Ovariotomy - WinckelPerineo.Plasty-Angerer-Excision of Knee for Tubercular Osteo. Myelitis-Heidelmeyer.

Dear Dr. Fenger:-When I arrived in Munich I felt at home, as I attended lectures here during the year 1878 . I remained for a whole week, and during this time saw many interesting cases with my

By permission of Drs. Fenger and Senn. former teacher of surgery, Professor Nussbaum, and Professors Winckel and Angerer. The Allgemeine Krankenhaus has undergone no change for the better since $I$ attended before. The University in this city now numbers I Ion medical students. Considering the number of universities in Germany and the large number of students in attendance almost everywhere, it becomes a serious question what is to become of these young men after their graduation. The country is now more than supplied with physicians, and if the increase continues for a number of years in the same ratio it is difficult to conceive in what way the medical men are to earn their daily bread.

The German government is well aware of the prevailing evil that too many graduates of the gymnasia choose the medical profession, and has taken steps to lead them into other channels by calling their attention to the existing evil through the columns or the public press. Only a few days ago Professor Hegar, of Freiburg, informed me that unless a decided change occurred in this direction the medical profession would soon degenerate into a "proletariat." It is well known that even at the present time, in some country towns, doctors will make visits, and even supply the necessary medicine, at half a mark. An ignorant "Dienstmann" would look with scorn at anything less than this for carrying your valise from the depot to the hotel. We have many cheap doctors in America, but their fees must be considered as royal when compared with such a beggarly sum. There is great danger that the same condition will prevail in America at no distant time, unless the medical colleges adopt timely measures to prevent over-crowding of the profession by elevating the standard for admission to the study of medicine as well as graduation. Nothing will degrade the profession so quickly in the eyes of the public as over-crowding. In the struggle for an existence men will resort to ways and means which they know are wrong.

It is quite a fashion in Europe, among medical men, to marry rich wives in order to keep the wolf from the door; but in my judgment such a course only aggravates the social and professional standing, as wealth acquired in such an easy way brings obligations which are antagonistic to scientific advancement. Unless a man acquires wealth by his own efforts he will seldom find his way into the front ranks of the profession. It is better for a man to remain poor as long as he lives, and labor honestly and perseveringly in the interests of his chosen profession, than to be constantiy handicapped by a rich wife or her many relatives. It is seldom that a rich woman has the good sense to satisfy her ambition in promoting the scientific attainments of her husband; her interests are usually outside of the things that pertain to the profession. Only too often her greatest, yes, her only desire is to become a conspicuous figure in society, and as she cannot attend the balls, receptions and theatres alone, the man who married her for her money must do at least what he can to make her happy, and must go along. In this way perhaps six evenings in the week are spent, and 
the books and medical journals, if money is spent for such things, become covered with dust.

That this picture is not overdrawn you can verify in your own city, where many of the richest doctors, who ought to occupy prominent positions among their colleagues, are not known outside the small circle of friends and acquaintances where they are tolerated only on account of their wealth. Science is making such rapid strides that its devotees have absolutely no time for the doubtful pleasures which society can offer. The good standing and purity of our profession can only be maintained by admitting into its ranks only men with natural adaptations and an innate love and devotion for the advancement of medical science and its collateral branches.

Contrary to several reports that I had received, I found Professor Nussbaum in tolerably good health, and attending to his duties in the hospital with the same regularity and enthusiasm as nine years ago. To those who have known him for many years his present condition is a mystery. During the FrancoPrussian war he suffered from coxitis, which left one of his hip joints in a contracted anchylosed condition, and since then he has had the misfortune of fracturing several of his bones; and yet after so much suffering and confinement he retains his mental vigor and works with the same enthusiasm as years ago. Physically crippled, mentally he is a giant. To follow such a man in his work for a few days ought to be enough for any man to stimulate him to follow such an illustrious example. Nuss. baum has been a hard worker all his life time, and his work bears the stamp of originality. His enthusiasm carries him sometimes too far, and yet these extremes have often been productive of a great deal of good. He was one of the first apostles of artiseptic surgery in Germany, and his little book (Leitfaden der antiseptischen Wundbehandlung) went through four editions, and did more towards the general adoption of antiseptic principles in the treatment of wounds than all the rest of the German literature combined; but he is familiar, at the same time, with the American and French authors and writers. His lectures are always interesting and fascinating, and the lecture room and operating theatre are always crowded with students.

During the time I remained in Munich I had the good fortune to see him perform three capital operations, which I will briefly detail. The first was an extirpation of a struma. The patient was a girl 25 years of age, who had noticed an enlargement of the neck when she was I 4 years of age. The swelling gradually increased in size until, for the last year, it has given rise to a great deal of discomfort, at times giving rise to suffocating sensations. The tumor was about the size of a hen's egg, located directly over the trachea. In his remarks on the operation attention was called to the serious consequences which have followed complete extirpation of the thyroid gland as described by Kocher under the title of cachexia strumi priva, as well as the results which have been obtained by experimental research. It was also stated that since complete excision has been abandoned tetanus had also disappeared from the statistics of struma operations. Kocher's incision along the anterior margin of the left sternocleidomastoid was made, and the tumor well exposed. Until the capsule was reached layer after layer was carefully divided and all hæmorrhage arrested. With blunt instruments the base of the tumor on each side was reached, and the parts containing the large vessels isolated into sections, and divided between two ligatures. By resorting to these precautions the operation was rendered almost bloodless. The trachea was found somewhat compressed, but sufficiently firm to retain its shape after the removal of the tumor. In cases in which the trachea has become so compressed and atrophied from pressure that after the removal there is danger of suffocation from sudden collapse or flexion, he resorts to amputation of the middle portion of the tumor over the trachea with Paquelin's cautery, so as to leave the part which supports the weakened portion of the trachea. Portions of both lateral lobes were left in this case. The cavity was filled with iodoform gauze and the skin partially united. The iodoform gauze tampon was intended for drainage, and was removed the next day, and the wound at this time was more carefully sutured.

The second case was an ovariotomy on a patient 67 years of age. The tumor had been noticed two years ago, but had increased in size rapidly for the last few months. The abdomen was moderately distended, fluctuating, uterus high, but in the pelvis a number of hard nodules could be felt. Attention was called to the difficulty of differentiating in some cases between ascites and ovarian cyst. In very obscure cases a positive diagnosis is only possible by an exploratory incision. During the operation the temperature of the room was at least $95^{\circ} \mathrm{F}$., which made not only the operator but all the students perspire freely. The abdomen and pubes were shaved and thoroughly disinfected the day before, and kept covered with a compress saturated with a carbolized solution. The abdominal incision was at least four inches in length. The tumor was tapped with a large straight trocar and drawn forward into the wound with forceps, and rapidly emptied by incision and crushing of smaller cyst with the hand introduced through the opening. The pedicle, broad and fleshy, was compressed with Helferich's constrictor, and the groove made tied with strong double catgut strings; below this point the pedicle was transfixed and tied in two parts, also with catgut. Above the first ligature the pedicle was again forcibly compressed between the blades of Langenbeck's forceps and burned off with Paquelin's cautery. The cleansing of the peritoneal cavity was done with large, soft sponges wrung out of a warm solution of carbolic acid. The abdominal wound was closed with a double row of chromatized catgut sutures and a typical Lister dressing applied.

All students are here admitted to laparotomies, and as the balcony above the operating table is usually crowded, it is remarkable that so few of the patients die of septic peritonitis.

The third case was another case of ovariotomy, also in an aged person. The tumor had been tapped 
twice, and each time a large quantity of fluid removed. tions and with a neatness and dispatch which would After each tapping a hard mass could be felt in the pelvis. The abdominal incision was again made long and led directly into the cyst, as the latter was firmly adherent. It took some time to find the point where the two surfaces were adherent. The adhesions were separated rapidly, and no attention paid to the oozing which occurred. The hard masses which had been felt in the pelvis after tapping proved to be smaller cysts, which were ruptured with the hand introduced through the opening made in the principal cyst. As the tumor had no adhesions in the pelvis, it could be readily brought out through the abdominal wound. The pedicle was treated in the same manner as in the previous case.

Two days later both patients were doing well. As the surroundings under which Nussbaum operates are by no means calculated to protect the patients against infection, we must attribute his good results to the careful antiseptic precautions which he follows before and during the operations and the manual dexterity which he has acquired after such a long and extensive experience in abdominal surgery.

A good deal of my time in Munich was spent in the lecture-room and wards of Professor Winckel. Professor Winckel is well and favorably known by his works on gynecology and childbed fever, as well as by his numerous valuable contributions to medical journals and society transactions. He organized the German Congress for Gynecology and was elected as its first President. He made an extensive tour through the United States and Canada last year, where he made valuable personal acquaintances. $\mathrm{He}$ is one of the leading gynecologists on the Continent, and has a better and more intimate acquaintance with the literature of his specialty than any other specialist. He is now writing a text-book on obstetrics, which will undoubtedly take the place of the most popular text-book on the same subject written by the lamented Carl Schroder. Professor Winckel has been a teacher almost since his graduation, and many of his pupils only a few years younger than himself are now distinguished surgeons and physicians. I was astonished when he told me that Professor Schoenborn, now of Würzburg, was one of his pupils, as the latter looks much older than his teacher. Winckel is a systematic worker, and never fails to make good use of his vacations to benefit his bodily health, and this undoubtedly explains his excellent physical condition. $\mathrm{He}$ is a great traveler and a most accurate observer. He is a hard student, a pleasant and forcible writer, a fascinating and enthusiastic teacher, a splendid diagnostician, and a bril liant and beautiful operator. $\mathrm{He}$ is a most valuable member of the Faculty, and will make his department one of the most attractive and successful in Europe. In his obstetrical wards the most scrupulous cleanliness prevails, and wherever necessary full antiseptic precautions are practiced, consequently indigenous cases of sepsis are almost unknown. His laparotomies are attended only by a few students, who must give proof that they have not been recently exposed to septic germs. I witnessed an ovariotomy in his wards which was don : under strict antiseptic precaube difficult to excel. The patient recovered without a single untoward symptom.

His private course on operative gynecology is unsurpassed by anything of this kind. The entire organs of generation of the female are removed from cadavers, preserved in an aqueous solution of corrosive sublimate, and kept ready for use. The soft parts are placed in a Schultze's phantom and attached in such an accurate manner that the normal relations are preserved. On such specimens the student is required to perform all the more important operations in gynecology under the immediate supervision of his teacher. Some of the students assist in the operations. When I was present the students were all arranged around three tables with as many operators, while Professor Winckel walked from place to place and directed the work. All teachers of gynecology should imitate this method of teaching, as it is the only way wnich will furnish adequate material for the different operations, and which will familiarize the students with the details of the most important operations.

I was very much interested in a case of perineoplasty which I witnessed. The laceration had extended into the rectum, and after vivifying the retracted margins of the rectal tear, coaptation was secured with silkworm-gut sutures passed through the entire thickness of the recto-vaginal wall and tied on the vaginal side. The perineum was sutured with the same material after Hegar's plan. Professor Winckel has performed this operation in many cases in this manner, and has never observed a recto-vaginal fistula after the operation. The recto-vaginal sutures are allowed to remain for several weeks.

Professor Angerer is the successor of Professor Helferich. now of Greifswald, and has charge of the polyclinic in the Reisingerianum. The operating room holds about roo students, and is daily crowded from i I to I2. A large clinical material collects here, and many important operations are performed, as the institution contains a few beds where patients can remain for a limited length of time. Angerer is a a good lecturer and an expert operator.

Among a number of operations that I saw here I was most interested in a case of excision of the kneejoint in a little boy suffering from tubercular osteomyelitis of the inner condyle of the femur, and consecutive fungous synovitis of the joint. On a previous occasion a tubercular spot had been removed from the inner tuberosity of the tibia. The joint was opened by a transverse incision and division of the ligamentum patellæ. 'When the patella was reflected it was found that the primary focus in the tibia had not healed, but had extended into the joint ; the internal condyle on opposite side of joint was the seat of a similar depot, also in communication with the joint. But the most remarkable condition was seen in the joint and recesses underneath the patella and quadriceps muscle. Only half of the joint was the seat of infection and secondary fungous proliferation, as the remaining portion of the joint, corresponding to the external condyle of the femur and the external tuberosity of the tibia, remained in 
a perfectly healthy, intact condition, being separated from the diseased portion by a partition of firm connective tissue. This is the condition which had been described to me by Professor Koenig a few weeks before, in which nature makes an attempt to localize the extension of tubercular processes, even in joints, by throwing out a wall of cicatricial tissue. Portions of the condyle and tuberosity were removed with the saw, and the healthy portion of the joint was left intact. The tendon of the patella was sutured and the wound closed, except at points where bone was removed, where tubular drainage was established. A copious dry sublimated dressing was applied and the limb placed upon a posterior splint.

I suggested to Professor Angerer after the operation that, under similar favorable circumstances, it would be advisable to split off the remaining portion of the internal condyle to draw it downward until it could be brought in apposition with the head of the tibia, where it could be retained with one or two aseptic bone-nails. Such a modification would secure a better support for the tibia, and prevent a tendency to the formation of a genu valgum during the reparative process.

Professor Angerer drills his students thoroughly in surgical diagnosis, and makes them familiar with important details which are usually ignored in the larger clinics. In connection with the polyclinic is a small laboratory where, under the direction of Professor Angerer, bacteriological studies are made and specimens from the clinic examined under the microscope. It is such a laboratory as I have urged should exist in connection with every chair of surgery, for the purpose of developing and teaching surgical pathology. Mr. Heilmeyer, who works in this laboratory, is an expert in preparing and mounting specimens, and as the sale of his slides is his principal source of income, he deserves the patronage of all who wish to promote the welfare and happiness of an humble but devoted promoter of the science of medicine.

During my stay in Munich I enjoyed the hospitality and friendship of Professor Winckel, and I fear I shall not be able to reciprocate his kindness unless he undertakes another tour through the United States, an event which would be looked for with pleasure by a host of his American friends.

N. SENN.

\section{LETTER FROM VIENNA}

(FROM OUR OWN CORRESPONDENT.)

Etiology and Treatment of Asthma caused by Polypi and Catarrhs-Dr. Pawik-Dr. Ehrendorfer.

At the last meeting of the Vienna "Doctoren-Collegium" Regierwngsrath Prof. Schnitzler made a valuable communication on the etiology and treat. ment of asthma. He above all wished to direct the attention to those cases of asthma which were caused by polypi of the nose and by nasal catarrhs, and which had been neglected for so long a time. Diseases of the nose were a frequent cause of asthma, and in most of cases polypi of the nose, and among these especially mucous polypi, gave origin to bronchial asthma. Often already a simple chronic nasal catarrh was a sufficient cause for producing asthmatic disturbances of a high degree. These disturbances, however, did not develop owing to narrowing or obstruction of the nasal cavities, and neither by the continuation of the catarrhal inflammatory process to the mucous membrane of the nose or the pharynx, etc., as was suggested by some authors. They were of a reflex nature, and due to the irritation of the nasal branches of the fifth nerve, and sometimes also the olfactory nerve, which, on the other hand, produced a reflex irritation of the vagus and the phrenicus nerves. This irritation produced the bronchial asthma with all its known symptoms. Hence, according to the opinion of Prof. Schnitzler, the asthma was an innervation disturbance of the respiratory process, being produced by reflex, and the asthma resulting from polypi of the nose or chronic nasal catarrhs was particularly to be looked upon as a reflex neurosis taking its origin in the nasal nerves. The reflex irritation of the vagus first led to a spasm of the bronchi, which was in most of cases also followed by a spasm of the diaphragm owing to the irritation of the phrenicus. At the same time vasomotor disturbances of the respiratory organs supervened-hyperæmia and augmented secretion of the bronchial mucous membrane-and the complex of the symptoms met with in cases of asthma was complete. But all the nerves mentioned above were not irritated in all cases of asthma, and all the organs which depended on them were not always affected either; sometimes the vaso-motor disturbances, and in other cases the spastic conditions, prevailed, and this fact accounted for the different explanations of the nature of asthma, each of which was justified, according to the opinion of Prof. Schnitzler.

Prof. Schnitzler then discussed the treatment of bronchial asthma, and especially that which was produced by polypi of the nose and nasal catarrhs, at full length. In cases of polypi of the nose, he had always obtained recovery of the asthma by removing the polypous affection, either by operation or by galvano caustic treatment. Before the asthmatic attack, he had often been able to cut it short by brushings of the nasal mucous membrane with a from 5 to ro per cent. solution of cocaine. He had also obtained good results with the administration of the iodide of potassium in combination with chloral hydrate. During the attack, chloral hydrate (administered by the mouth or by means of clysters), and injections of morphine. proved as the proportionately most efficient agents, but their effect was nevertheless not so constant as had been stated by some authors. The fumigations with saltpetre, stramonium, pyridin, etc., proved in some cases to be efficient; in others they failed to do so. As to amyl nitrite, the nitrate of silver, and nitroglycerine, they had a better effect in cases of cardial asthma than in bronchial asthma. Prof. Schnitzler passed an interesting and critical review of all the remedies which had been recommended in the treatment of asthma-the agents for precipitating the secretion, the climate, and pneumato-therapeutics, etc. and objected to the efficiency of most of them; a fact which is very plausible, considering that the known Vienna laryngologist was 